\title{
KELEMBAGAAN PENGELOLAAN MANGROVE BERBASIS MASYARAKAT DI KESATUAN PENGELOLAAN HUTAN MODEL WILAYAH III PROVINSI ACEH, INDONESIA
}

\section{Community-Based Mangrove Management Institutions In The Model lii Forest Management Unit In Aceh Province, Indonesia}

\section{OK Hasnanda Syahputra ${ }^{1}$, Bramasto Nugroho ${ }^{2}$, Hariadi Kartodihardjo ${ }^{2}$ Nyoto Santoso ${ }^{3}$}

${ }^{1}$ Program Studi Kehutanan, Fakultas Kehutanan, Universitas Sumatera Utara, Medan

${ }^{2}$ Departemen Manajemen Hutan, Fakultas Kehutanan, Universitas IPB Bogor,

${ }^{3}$ Departemen Konservasi Hutan, Fakultas Kehutanan, Universitas IPB Bogor

*Email : okhasnanda@usu.ac.id

Diterima : 26/07/2020, Direvisi : 27/08/2020, Diterbitkan 01/03/2021

\begin{abstract}
Institutional community-based mangrove management as an alternative to sustainable management of mangrove forests. This study aims to analyze which factors from the institution most play a role in guiding the community in managing mangrove forest resources in relation to forest management units (FMU). Primary data were collected through interviews conducted semi-structured to 26 respondents selected by the purposive sampling method. The snowball method is used to capture information from key figures. Deepening is considered complete if information saturation has occurred which is marked by repetition of the same information. While secondary data, obtained from various libraries. Of the three models of mangrove management institutions, namely the community institution of Pusong Kapal Village (PKV), the community institution of Pusong Telaga Tujoh Village (PTTV), and the Community Forestry (CF-BM) Bina Mufakat institution where the analysis shows that the community institutions of Pusong Kapal Village (PKV) are more flexible as an alternative form of community-based mangrove management institutions, because this institution is able to adapt to the changing social and environmental conditions that continue to occur, the collaboration of management with the government, and the recognition of community rights in the use of mangrove forests. FMU as the management authority at the site level has guaranteed the upholding of the rights of the PKV community as the manager of mangrove forests so that the bundle of rights and incentives obtained in the management of mangrove resources by PKV communities becomes strong.
\end{abstract}

Keywords; Mangrove, Stakeholders, Network, Forest Management Unit

\section{ABSTRAK}

Kelembagaan pengelolaan mangrove berbasis masyarakat, sebagai alternatif pengelolaan hutan mangrove secara berkelanjutan. Penelitian ini bertujuan untuk menganalisis faktor-faktor mana dari kelembagaan yang paling berperan memandu masyarakat dalam pengelolaan sumber daya hutan mangrove kaitannya dengan kesatuan pengelolaan hutan $(\mathrm{KPH})$. Data terdiri dari data primer dan data skunder. Data primer 
dikumpulkan lewat wawancara yang dilakukan secara semi terstruktur terhadap 26 responden yang dipilih dengan metode purposive sampling. Metoda snowball digunakan untuk menjaring informasi dari tokoh-tokoh kunci. Pendalaman dianggap selesai jika telah terjadi kejenuhan informasi yang ditandai dengan pengulangan informasi yang sama. Sedangkan data sekunder, diperoleh dari berbagai kepustakaan. Dari ketiga model kelembagaan pengelolaan mangrove, yaitu kelembagaan masyarakat Desa Pusong Kapal (DPK), kelembagaan masyarakat Desa Pusong Telaga Tujoh (DPTT), dan Hutan kemasyarakatan (HKm-BM) Bina Mufakat, dimana hasil analisis menunjukkan bahwa kelembagaan masyarakat Desa Pusong Kapal (DPK) lebih fleksibel sebagai alternatif bentuk kelembagaan pengelolaan mangrove berbasis masyarakat, karena lembaga ini mampu beradaptasi dengan perubahan kondisi sosial dan lingkungan yang terus terjadi, adanya kolaborasi pengelolaan dengan pemerintah, dan adanya pengakuan hak-hak masyarakat dalam pemanfaatan hutan mangrove tersebut. KPH sebagai otoritas pengelola di tingkat tapak telah memberi jaminan tegaknya hak-hak bagi masyarakat DPK sebagai pengelola hutan mangrove sehingga bundel hak dan insentif yang diperoleh dalam pengelolaan sumber daya mangrove oleh masyarakat DPK menjadi kuat..

Kata kunci; Kelembagaan, Pengelolaan Berbasis Masyarakat, KPH

\section{PENDAHULUAN}

Konsep pengelolaan hutan mangrove berbasis masyarakat merupakan suatu keniscayaan karena potensi keterlibatan masyarakat lokal merupakan bagian penting dalam mengidentifikasi sumber daya, prioritas pengembangan, pilihan dan adaptasi teknologi tepat guna untuk merumuskan dan menerapkan praktik pengelolaan yang berkelanjutan. Secara lebih luas konsep ini mengacu pada desentralisasi hak, tanggung jawab, dan wewenang dari pemerintah untuk masyarakat lokal dalam mengelola sumber daya alam (Alcoorn et al. 2002). Lebih konkretnya bahwa pengelolaan hutan mangrove berbasis masyarakat adalah bagaimana cara masyarakat lokal lebih patuh melaksanakan aturan dalam mengatur kelembagaannya sehingga lebih mungkin memiliki hutan dengan kondisi yang baik. Kelompok-kelompok lokal setidaknya sebagai pengelola yang efektif (Hayes 2006; Nelson dan Chomitz 2009). Artinya untuk memediasi interaksi manusia dan penggunaan sumber daya alam, mereka peduli terhadap kesejahteraan ekonomi lokal yang tergabung dengan kepentingan konservasi, tekanan faktor eksogen, dan pengakuan nilai lokal (Agrawal dan Gupta 2005; Brockington 2007).

Berdasarkan tujuan analisis kelembagaan, Hidayat (2005) mengemukakan pendapatnya bahwa kelembagaan, baik formal maupun informal, adalah aturan main bagi sekelompok orang, masyarakat atau organisasi yang tujuannya adalah untuk meningkatkan kepastian dan prediktabilitas interaksi antara manusia yang dengan jelas mendefinisikan batas-batas tindakan yang sah. Harapannya adalah bahwa aturan-aturan ini dapat memberikan sebuah tatanan sosial yang bebas dari perilaku tidak produktif opportunistic dan lainnya. Dengan kata lain, kelembagaan adalah aturan main yang disepakati oleh sekelompok orang atau organisasi untuk mengelola sumber daya tertentu yang menentukan siapa yang boleh mengelola sumber daya apa, di mana, kapan, dan bagaimana (Muttaqin 2012).

Walaupun pengelolaan hutan berbasis masyarakat dipandang sebagai salah satu pengelolaan hutan yang tepat untuk mendukung pengelolaan lestari (Berkes 2008), namun ada juga yang menunjukkan hasil berbeda. Dimana tidak semua pengelolaan hutan berbasis masyarakat tersebut berhasil mengontrol akses dan pemanfaatan sumber daya alam secara berkelanjutan disebabkan oleh fokus pengelolaan yang tanpa mempertimbangkan kerangka kelembagaan di lokasi pengelolaan tersebut (Ostrom 1990; Sithole 1997). Kerusakan ini terutama akibat dari penggunaan yang tidak efesien oleh 
sebagian besar masyarakat yang tergantung pada hutan, sistem manajemen top-down, dan hak milik negara (Roy et al. 2012).

Untuk mengatasi degradasi ini, banyak negara-negara berkembang telah mengadopsi co-management (Adhikari dan Goldey 2010). Metode co-management dirancang untuk memberdayakan dan mengamankan mata pencaharian masyarakat lokal (Bhattacharya et al. 2010). Dalam pengaturan ini, Kesatuan Pengelolaan Hutan (KPH) menyediakan wadah bagi terselenggaranya kegiatan pengelolaan hutan secara efesien dan lestari dengan memberikan otonomi dan beberapa kekuatan kepada kelompok masyarakat setempat. Kemitraan ini sebagai bentuk terbaik dari kolaborasi, karena keputusan ditentukan melalui konsensus. Peran kelembagaan pengelolaan hutan mangrove berbasis masyarakat akan berhasil apabila mampu mengintegrasikan masyarakat dalam perlindungan dan penjagaan ekosistem mangrove. Masyarakat memiliki peran apabila tersedianya ruang bagi pendekatan partisipatif dalam pengelolaan sumberdaya hutan mangrove. Beberapa hasil penelitian telah membuktikan, pengelolaan mangrove berbasis masyarakat telah memberikan manfaat dan meningkatkan ekologi hutan mangrove (Schweik 1998; Ostrom 1999; Harrison dan Suh 2004; Agrawal dan Chhatre 2006; Sudtongkong dan Webb 2008).

Kehadiran KPH di Provinsi Aceh dilakukan dengan menetapkan 7 (tujuh) KPH ditingkat Provinsi yang pembentukannya berbasis pada Daerah Aliran Sungai (DAS). KPH model wilayah III merupakan Kesatuan Pengelolaan Hutan Lindung (KPHL) meliputi kelompok DAS Krueng Jambo Aye, Krueng Peurelak, dan Krueng Tamiang, ditetapkan berdasarkan Surat Keputusan Menteri Kehutanan Nomor: 993/Menhut-II/2013 tanggal 27 Desember 2013 dengan luas wilayah 682.391 ha, terdiri dari hutan produksi tetap 276.118 ha dan hutan lindung 406.273 ha. Sedangkan luasan hutan mangrove berkisar \pm 20.481 ha. Untuk memperkuat landasan operasional pelaksanaan di lapangan, ditetapkan pula Peraturan Gubernur Aceh Nomor: 20 Tahun 2013 Tanggal 12 April 2013 tentang Susunan Organisasi dan Tata Kerja Unit Pelaksana Teknis Dinas Pada Dinas Kehutanan Aceh.

Dalam mengkaji kelembagaan lokal untuk pengelolaan sumber daya alam, ada dua pendekatan yang dilakukan. Pertama, bagaimana lembaga-lembaga lokal yang bekerja pada level lokal mampu berkolaborasi dan berinteraksi dengan pihak-pihak luar. Mengembangkan kelembagaan lokal dengan memahami prinsip-prinsip Ostrom sebagai langkah untuk memahami potensi hubungan antara lembaga-lembaga tersebut. Kedua, dengan berfokus pada lembaga-lembaga lokal dalam prinsip-prinsip rancangannya yang sangat jelas bukan hanya dengan sifat-sifat lembaga yang bertahan lama, namun prinsipprinsip rancangan lembaga-lembaga tersebut dapat beradaptasi dengan perubahan lingkungan sepanjang waktu. Oleh karena itu, perlu dirumuskan faktor-faktor apa yang bisa menjelaskan perbedaan hasil tersebut. Karenanya, penelitian ini menjawab pertanyaan dengan berfokus pada faktor-faktor mana dari kelembagaan yang paling berperan memandu masyarakat dalam pengelolaan sumber daya hutan mangrove. Hasil analisis diharapkan dapat digunakan untuk mengatasi permasalahan institusi dalam pengelolaan hutan mangrove berbasis masyarakat pada KPH Model Wilayah III.

\section{METODE}

\section{A. Waktu dan Lokasi Penelitian}

Kegiatan penelitian dilaksanakan pada bulan Agustus-Desember 2016. Penelitian ini dilaksanakan di tiga kelembagaan pengelolaan mangrove dalam areal kerja KPH Model Wilayah III Provinsi Aceh, yakni kelembagaan pengelolaan mangrove berbasis masyarakat Desa Pusong Kapal (DPK) di Kabupaten Aceh Tamiang, Desa Pusong Telaga Tujuh 
(DPTT) di Kota Langsa, dan Hutan Kemasyarakatan Bina Mufakat (HKm-BM) di Kabupaten Aceh Timur.

\section{B. Metode Pengumpulan dan Analisis Data}

Penelitian ini dilakukan melalui pendekatan studi kualitatif menggunakan data primer dan sekunder, meliputi faktor eksogen (kondisi biofisik, atribut komunitas, dan aturan dalam pengelolaan mangrove). Data penelitian ini berasal dari observasi, wawancara informan kunci, dan analisis dokumen. Wawancara semi terstruktur dilakukan kepada 26 responden yang terpilih antara lain 3 responden dari masyarakat di tiga desa yang melakukan pengelolaan mangrove, tokoh masyarakat 3 responden, kepala desa 3 responden, Lembaga Swadaya Masyarakat 2 responden, instansi pemerintah terkait 13 responden, dan perguruan tinggi 2 responden.

Pengolahan dan analisis data dilakukan secara kualitatif melalui metode tabulasi dan deskriptif. Analisis kelembagaan mengunakan kerangka IAD framework dari Ostrom (2005), diikuti oleh evaluasi kinerja kelembagaan dan keberhasilannya, dengan pendekatan variabel eksogen dan variabel endogen (Ostrom 2005; McGinnis 2011; Ostrom 2011). Variabel eksogen meliputi kondisi biofisik dan material, atribut komunitas, dan aturan yang digunakan. Sedangkan variabel endogen adalah arena aksi yang terdiri dari situasi aksi dan partisipan.

Penilaian kinerja kelembagaan menggunakan prinsip desain Ostrom (1990), telah mencatat beberapa indikator kinerja institusi pengelolaan sumber daya adalah sebagai berikut: 1) Kejelasan batas wilayah. Batas wilayah dirumuskan secara jelas sehingga setiap orang mudah untuk mengidentifikasi dan mengenalnya; 2) Kesesuaian aturan dengan kondisi setempat (lokal); 3) Aturan disusun dan dikelola oleh pengguna sumber daya, dimana masyarakat mampu membuat aturan didasarkan atas pengetahuan lokal maupun kearifan lokal melalui mekanisme lembaga lokal. Lembaga lokal berfungsi mengatur mekanisme pengelolaan, membuat aturan, merevisi aturan serta mekanisme pengambilan keputusan; 4) Pelaksanaan pengawasan dihormati masyarakat. Masyarakat memiliki instrumen dan mekanisme pengawasan sendiri dengan para pelaku pengawasan yang mendapat legitimasi masyarakat; 5) Berlakunya sanksi. Ukuran keberhasilan suatu aturan adalah tegaknya sanksi bagi para pelanggarnya, baik sanksi sosial, sanksi administratif, maupun sanksi ekonomi; 6) Mekanisme resolusi konflik. Masyarakat memiliki mekanisme alternatif dalam penyelesaian konflik di luar mekanisme formal; 7) Kuatnya pengakuan pemerintah, dapat berbentuk undang-undang, peraturan pemerintah atau peraturan daerah; 8) Adanya ikatan atau jaringan dengan lembaga luar, yaitu baik jaringan antar komunitas maupun di luar komunitas seperti perguruan tinggi, LSM maupun swasta.

Data sekunder dalam penelitian ini merupakan data pendukung yang diperoleh dari berbagai pustaka, seperti kondisi ekosistem hutan berupa data analisis vegetasi dengan menghitung jumlah individu vegetasi per hektar pada tingkat semai, pancang dan pohon.

Dalam proses pembentukan co-manajemen dapat dimulai dari proses ko-operasi, kemitraan, dan kolaborasi (Anshari 2006). Mekanisme partisipasi hanya dapat berjalan, jika ada hak seluruh pemangku kepentingan untuk mengakses dan mendapatkan informasi rencana-rencana kegiatan serta usulan-usulan kegiatan yang dapat memberikan manfaat dan keuntungan untuk seluruh pemangku kepentingan. Tingkatan partisipasi menuju terwujudnya pengelolaan co-manajemen dapat dilihat pada Tabel 1. 
Tabel 1 Tingkatan Partisipasi menuju terwujudnya pengelolaan co-manajemen Tabel 1 Level of participation leading on the realization of Co-management

\begin{tabular}{lll}
\hline No Pendekatan & Tingkatan (kadar) partisipasi \\
\hline 1 Non-partisipasi & Pemilik proyek atau agenda bertindak sebagai inisiator, \\
& yang menentukan agenda, dan mengatur, mengawasi, \\
& serta mengevaluasi kegiatan-kegiatan proyek. Pada \\
& tingkatan ini, pemilik proyek dapat melibatkan pihak lain \\
& untuk melaksanakan sebagian atau seluruh kegiatan \\
& proyek dengan imbalan. Pihak lain tersebut \\
& kemungkinan bertindak sebagai konsultan atau \\
& kontraktor. \\
\hline Ko-operasi & Pemilik agenda atau proyek mendapatkan masukan \\
& masukan dari para pemangku kepentingan, dan \\
& kemudian menganalisis masukan-masukan tersebut. \\
& Setelah itu pemilik proyek atau agenda tersebut \\
& menyusun rencana, melaksanakan kegiatan, dan \\
& mengevaluasi hasil-hasil kegiatan proyek. \\
\hline Kemitraan & Pemilik atau pengusul proyek atau agenda bersama \\
& pemangku kepentingan lain yang telah bersepakat \\
& membentuk kemitraan dan bersama-sama menentukan \\
& agenda kegiatan. Dalam hal ini pemilik yang pertama \\
& kali mengusulkan proyek atau agenda memimpin \\
& pelaksanaan kegiatan dan bertanggung jawab atas \\
hasil-hasil kegiatan. & \\
\hline Kolaborasi & Proyek atau agenda diusulkan dan dirancang bersama. \\
& Para pemangku kepentingan setara dan bersama-sama \\
& mengidentifkasi permasalahan, merumuskan kegiatan, \\
& dan mengevaluasi hasil-hasil kegiatan. Proses belajar \\
& dilakukan bersama-sama secara terus menerus, dan \\
& rencana-rencana kegiatan disusun secara adaptif dan \\
& lentur (fleksibel). Pada tahapan ini, diperlukan fasilitator \\
& untuk mempercepat proses-proses kolaborasi. \\
& Peranan fasilitator sebagai pengamat proses-proses, \\
& penasehat dan tidak menentukan arah ataupun \\
& melakukan intervensi
\end{tabular}

Sumber : Modifikasi dari Cornwall dan Jewkes (1995).

\section{HASIL DAN PEMBAHASAN}

\section{A. Tipologi Kelembagaan di Wilayah Studi dan Arena Aksi}

Kelembagaan adalah aturan main, norma-norma, larangan-larangan, kontrak dan sebagainya dalam mengatur dan mengendalikan prilaku individu dalam masyarakat atau organisasi (North 1990). Ostrom (1990) mendefinisikan kelembagaan sebagai seperangkat aturan kerja yang digunakan untuk menentukan siapa yang berhak untuk membuat keputusan dalam beberapa arena, tindakan apa yang diperbolehkan atau dibatasi, apa aturan agregasi akan digunakan, prosedur apa yang harus diikuti, informasi yang harus tidak 
diberikan, dan apa yang akan diberikan kepada individu tergantung pada tindakan mereka. Knight (1992), menganggap kelembagaan menjadi seperangkat aturan dari struktur interaksi sosial dengan cara-cara tertentu. Bromley (1989) juga menganggap konvensi dan hak sebagai kelembagaan. Oleh karenanya kelembagaan, dipahami sebagai aturan yang memberikan makna dan stabilitas kehidupan sosial (Scott 2008).

Untuk mengidentifikasi kelembagaan di wilayah studi, perlu diketahui tipologi dari masing-masing kelembagaan yang diamati seperti pada Tabel 2.

Tabel 2 Tipologi kelembagaan pada tiga wilayah studi

Table 2 Institutional typologies in the three study areas

\begin{tabular}{|c|c|c|c|}
\hline \multirow{2}{*}{ Tipologi Kelembagaan } & \multicolumn{3}{|l|}{ Wilayah Studi } \\
\hline & Masyarakat DPK & Masyarakat DPTT & HKm Bina Mufakat \\
\hline Betuk kelembagaan & Informal & Informal & Formal \\
\hline Norma aturan & $\begin{array}{l}\text { Tertulis dan Tak } \\
\text { tertulis }\end{array}$ & Tak tertulis & Tertulis \\
\hline Pengambilan & & Musyawarah & Top-down \\
\hline $\begin{array}{l}\text { keputusan } \\
\text { Sifat kelembagaan }\end{array}$ & $\begin{array}{l}\text { Musyawarah } \\
\text { Elastis, dapat berubah } \\
\text { sesuai dengan }\end{array}$ & $\begin{array}{l}\text { Elastis, dapat berubah } \\
\text { sesuai dengan } \\
\text { keadaan }\end{array}$ & Kaku \\
\hline $\begin{array}{l}\text { Model kelembagaan } \\
\text { Luas mangrove }\end{array}$ & $\begin{array}{l}\text { keadaan } \\
\text { Co-management } \\
\pm 361 \text { ha }\end{array}$ & $\begin{array}{l}\text { Murni masyarakat } \\
\pm 230 \text { ha }\end{array}$ & $\begin{array}{l}\text { Skema pemerintah } \\
\pm 6.095 \text { ha }\end{array}$ \\
\hline
\end{tabular}

Sumber: Data primer diolah (2016)

Source : Processed primary data (2016)

Berdasarkan Tabel 2, tipologi kelembagaan pada tiga wilayah studi memperlihatkan bahwa kelembagaan pada masyarakat DPK dan masyarakat DPTT berbentuk kelembagaan informal sedangkan pada masyarakat $\mathrm{HKm}$ bentuk kelembagaan formal. Model kelembagaan pada masyarakat DPK yaitu co-management, pada masyarakat DPTT dengan model murni masyarakat, dan pada HKm dengan model skema pemerintah. Ada cukup bukti untuk menunjukkan bahwa sistem terpusat top-down tidak efektif untuk mengatur sumber daya alam, seperti hutan dan air (Carlson dan Sandstrom 2008). Comanagement sebagai solusi alternatif yang potensial untuk masalah pengelolaan lingkungan berkelanjutan. Karenanya keberhasilan co-management akan terwujud jika ada keseimbangan antara para pihak dalam perjanjian tentang bagaimana kekuasaan dialokasikan dan berbagi. Pembagian kekuasaan sebagai ciri mutlak dari co-management (Roy dan Alam 2012). Namun, co-management akan gagal jika tidak bisa memecahkan masalah tekanan penduduk dan tuntutan keberlanjutan mata pencaharian masyarakat setempat. Hal ini terjadi sebagai akibat kegagalan struktur (mekanisme resolusi konflik, pengaturan kelembagaan rapuh, mekanisme akuntabilitas tidak efesien, dan kolaborasi yang buruk) co-management untuk membawa ke keseimbangan konflik inheren antara pengelolaan lestari dan pemenuhan mata pencaharian (Mukul et al. 2010). Pengaturan kelembagaan dapat berkembang ketika orang menyadari bahwa sumber daya mangrove menjadi langka maka dibutuhkan kewaspadaan mengenai pemanfaatan hutan yang berlebihan. 
Kelembagaan masyarakat DPK dan masyarakat DPTT mempunyai bentuk kesamaan, dimana kelembagaan tersebut terbentuk karena didasari oleh pengalaman sejarah kehidupan masyarakat yang langsung berhubungan dengan hutan mangrove. Seperti diketahui bahwa kedua desa tersebut sangat ketergantungan dengan keberadaan mangrove yang berfungsi sebagai penyangga yang melindungi kedua desa dari banjir rob, terpaan angin dan sebagainya. Dengan kata lain, kelembagaan lahir karena didorong adanya pengalaman sejarah kehidupan yang sama didalam masyarakat, usaha dan niatan untuk menjaga keberlangsungan mangrove, dan adanya rasa senasib sepenanggungan terhadap bencana yang ditimbulkan akibat dari kerusakan mangrove. Oleh karenanya suksesnya suatu kelembagaan bukan karena keberhasilan keberlanjutan kelembagaan itu, tetapi karena mampu melalui berbagai krisis dengan bertahan dan beradaptasi untuk jangka waktu yang lama.

\section{B. Keberlanjutan kelembagaan}

Fungsi keberlanjutan dan kapasistas adaptif lembaga masyarakat merupakan faktor penting meningkatkan inisiatif untuk jangka waktu yang panjang. Keberlanjutan kelembagaan mengacu pada kompetensi lembaga, kordinasi, intraksi dalam rangka memfasilitasi dan mengeksekusi pengambilan keputusan. Disisi lain, memahami proses perubahan kelembagaan sangat penting untuk memahami stabilitas sumber-sumber kelembagaan, dan inersia kelembagaan (Cabalerro et al. 2014). Hal ini membutuhkan lebih dari hanya melestarikan lembaga. Kenyataaannya, lembaga harus mematuhi proses sosial-politik, mendorong partisipasi dalam pengambilan keputusan dan bertanggung jawab kepada kebijakan keberlanjutan. Karenanya, keberlanjutan kelembagaan membutuhkan banyak perhatian sebagai investasi awal. Aspek utama keberlanjutan kelembagaan adalah bagaimana para individu secara kumulatif membentuk lembaga lokal berbagi hak milik dan distribusi sumber daya dan akses. Nugroho (2013) menegaskan bahwa kelembagaan dikatakan baik, apabila aturan main dan organisasi mampu mengarahkan perilaku para pihak-pihak yang terlibat dan saling terkait untuk mencapai tujuan-tujuan bersama (common goals).

Tabel 3 menunjukkan prinsip-prinsip desain yang diidentifikasi terkait dengan keberlangsungan ketahanan lembaga yang digunakan untuk mengatur sumber daya alam milik bersama (Ostrom 2005). Ketangguhan lembaga dalam memelihara sistem kinerja yang diinginkan ketika mengalami gangguan baik dari eksternal maupun internal (Carlson dan Doyle 2002). Prinsip-prinsip desain ini dapat mensintesis faktor inti yang mempengaruhi kelangsungan jangka panjang dari lembaga yang mengelola sumber daya milik bersama (Ostrom 2005). 
Tabel 3 Keberlanjutan model institusi pada tiga wilayah studi

Table 3 Sustainability of institutional models in the three study areas

\begin{tabular}{|c|c|c|c|}
\hline \multirow{2}{*}{ Prinsip } & \multicolumn{3}{|c|}{ Masyarakat } \\
\hline & DPK & DPTT & $\mathrm{HKm}$ \\
\hline $\begin{array}{l}\text { Batas terdefinisi } \\
\text { dengan jelas } \\
\text { Sumber daya }\end{array}$ & $\begin{array}{l}\text { Sudah tata batas, } \\
\text { diketahui dan } \\
\text { disepakati bersama } \\
\text { (ya) }\end{array}$ & $\begin{array}{l}\text { Batas tidak jelas, } \\
\text { diketahui dan } \\
\text { disepakati bersama } \\
\text { (ya) }\end{array}$ & $\begin{array}{lr}\text { Sudah tata batas, } \\
\text { patok } & \text { batas } \\
\text { banyak } & \text { yang } \\
\text { hilang } & \text { (sebagian }\end{array}$ \\
\hline r crigguna & $\begin{array}{l}\text { Masyarakat DPK } \\
\text { (ya) }\end{array}$ & $\begin{array}{l}\text { Masyarakat DPTT } \\
\text { (ya) }\end{array}$ & $\begin{array}{l}\text { ljin pengguna, } \\
\text { tetapi banyak } \\
\text { terjadi ekstraksi } \\
\text { liar (sebagian ya) }\end{array}$ \\
\hline Monitoring & & & \\
\hline $\begin{array}{l}\text { Proses monitoring } \\
\text { dilakukan secara aktif } \\
\text { oleh lembaga local }\end{array}$ & $\begin{array}{l}\text { Diawasi oleh } \\
\text { lembaga local dan } \\
\text { bekerjasama } \\
\text { dengan KPH (ya) }\end{array}$ & $\begin{array}{l}\text { Diawasi oleh } \\
\text { lembaga local (ya) }\end{array}$ & $\begin{array}{l}\text { Diawasi oleh } \\
\text { pengurus HKm } \\
\text { (sebagian ya) }\end{array}$ \\
\hline Penerapan sanksi & $\begin{array}{l}\text { Sanksi bertingkat } \\
\text { dan dipatuhi (ya) }\end{array}$ & $\begin{array}{l}\text { Sanksi bertingkat } \\
\text { dan dipatuhi (ya) }\end{array}$ & $\begin{array}{l}\text { Sanksi dalam } \\
\text { aturan tapi minim } \\
\text { dalam penerapan } \\
\text { (ya) }\end{array}$ \\
\hline $\begin{array}{l}\text { Mekanisme resolusi } \\
\text { konflik }\end{array}$ & Musyawarah (ya) & Musyawarah (ya) & $\begin{array}{l}\text { Proses hokum, } \\
\text { biaya mahal tidak } \\
\text { efektif (sebagain } \\
\text { ya) }\end{array}$ \\
\hline $\begin{array}{l}\text { Pengakuan hak } \\
\text { dalam mengatur } \\
\text { Hak otoritas local } \\
\text { dalam merancang } \\
\text { kelembagaan dan } \\
\text { kerjasama dengan }\end{array}$ & $\begin{array}{l}\text { Mempunyai hak } \\
\text { yang sama (ya) }\end{array}$ & $\begin{array}{l}\text { Mempunyai hak } \\
\text { yang sama (ya) }\end{array}$ & $\begin{array}{l}\text { Ketentuan yang } \\
\text { sudah diatur } \\
\text { berdasarkan top } \\
\text { down (tidak) }\end{array}$ \\
\hline $\begin{array}{l}\text { Tidak ada kelompok } \\
\text { pengguna yang dapat } \\
\text { mencegah pengguna } \\
\text { lain mengorganisasi } \\
\text { diri dan melembaga }\end{array}$ & $\begin{array}{l}\text { Prinsip pemerataan } \\
\text { asset, pemanfaatan } \\
\text { yang berkeadilan } \\
\text { dan berkelompok } \\
\text { (ya) }\end{array}$ & $\begin{array}{l}\text { Prinsip pemerataan } \\
\text { asset, pemenfaatan } \\
\text { yang berkeadilan } \\
\text { dan berkelompok } \\
\text { (ya) }\end{array}$ & $\begin{array}{l}\text { Tidak ada } \\
\text { kelompok } \\
\text { pengguna, tidak } \\
\text { independen (tidak) }\end{array}$ \\
\hline $\begin{array}{l}\text { Bagian dari system } \\
\text { pengelolaan } \\
\text { Keterkaitan antara } \\
\text { aturan yang } \\
\text { ditegakkan }\end{array}$ & $\begin{array}{l}\text { Terdapat } \\
\text { keterkaitan antara } \\
\text { aturan formal dan } \\
\text { aturan informal }\end{array}$ & $\begin{array}{l}\text { Terdapat } \\
\text { keterkaitan antara } \\
\text { aturan formal dan } \\
\text { informal, namun } \\
\text { tidak saling } \\
\text { memperkuat }\end{array}$ & $\begin{array}{l}\text { Tidak memiliki } \\
\text { aturan yang jelas }\end{array}$ \\
\hline
\end{tabular}

Sumber: data primer diolah (2016); Ostrom (1990); Nursidah (2012)

Source : Primary data processed (2016); Ostrom (1990); Nursidah (2012) 
Pada Tabel 3 terlihat bahwa, kelembagaan masyarakat DPK memiliki tingkat keberlanjutan yang paling baik, dikarenakan pada kelembagaan ini aturan-aturan yang mengatur individu diikuti dan ditegakkan oleh anggota kelompoknya. Begitu pula dengan pemberian sanksi kepada anggota kelompok atau di luar kelompok yang melanggar aturan.

Evaluasi terhadap kelembagaan pengelolaan mangrove berbasis masyarakat memperlihatkan bahwa kelembagaan yang berdasarkan norma adat relatif lebih unggul dibandingkan dengan kelembagaan yang diterapkan pemerintah. Semua faktor yang menjadi kajian berpengaruh positif terhadap keberlanjutan. Kondisi ini lebih cocok dengan karateristik pengelolaan CPRs sebagai bentuk pengelolaan milik bersama dalam bentuk aksi kolektif. Pengaturan kelembagaan yang dirancang dengan menggabungkan mekanisme perilaku yang memfasilitasi kerjasama dapat meningkatkan kepatuhan dalam menerapkan aturan. Batas-batas sosial yang jelas, pemantauan dan sanksi akan menaikkan tingkat kepercayaan orang atau kelompok masyarakat untuk bekerjasama pula. Bentuk kerjasama yang telah dilakukan oleh masyarakat DPK dengan KPH model wilayah III berupa patroli hutan dalam mengamankan area mangrove di wilayahnya. Namun, sanksi yang diterapkan tidak akan berefek positif pada panen bruto sumber daya kecuali dikombinasikan dengan komunikasi (Janssen et al. 2010). Jelasnya, dalam menggunakan aturan dan mekanisme sanksi lokal yang ketat mungkin akan memperbaiki kondisi hutan di wilayah tersebut dan tampaknya akan efektif dalam menangani masalah substractability, yang telah didefinisikan dengan baik dan aturan yang jelas untuk mengatur penggunaan sumber daya.

Dari uraian di atas, membuktikan bahwa masyarakat DPK dan masyarakat DPTT telah mampu membuat dan menerapkan aturan kelembagaan yang membentuk interaksi dan mengatur perilaku individu-individu diantara anggota masyarakat dengan sumberdaya dan membantu mereka dalam usaha melindungi dan mendistribusikan sumberdaya mereka secara adil, efesien dan lestari.

\section{Keberlanjutan Ekologi}

Ekosistem mangrove merupakan sumberdaya alam yang mempunyai manfaat ganda dengan pengaruh yang sangat luas bila ditinjau dari aspek sosial ekonomi dan sangat penting dalam memberikan jasa lingkungan. Berkonstribusi langsung dan tidak langsung untuk mata pencaharian jutaan penduduk pesisir (Soontornwong 2006). Sistem akar yang unik menangkap sedimen dan mencegah erosi/abrasi (Kathiresan dan Bingham 2001). Salah satu hutan yang paling efisien penyerap karbon dibandingkan dengan sistem hutan lainnya (Pidgeon 2009). Hutan mangrove di wilayah pesisir membuat dampak nyata mengurangi tinggi gelombang dan dampak tsunami (Phan Nguyen Hong 2006), mencegah intruisi air laut, habitat perikanan dan keseimbangan lingkungan di samping sebagai penghasil kayu dan lainnya (Kusmana 2012). Keberlanjutan ekologi mangrove di tiga wilayah studi dapat dilihat pada Tabel 4. 
Tabel 4 Keberlanjutan Ekologis Hutan Mangrove di tiga Wilayah Studi Table 4 Ecological sustainability of mangrove forests in the three study areas

\begin{tabular}{|c|c|c|c|c|c|}
\hline Lokasi & Peneliti & Klasifikasi & $\begin{array}{c}\text { Jumlah } \\
\text { Jenis }\end{array}$ & $\begin{array}{c}\text { Kerapatan } \\
\text { Total } \\
\text { (Individu/ha) }\end{array}$ & $\begin{array}{c}\text { Kondisi Hutan } \\
\text { Mangrove }\end{array}$ \\
\hline Langsa & $\begin{array}{l}\text { Majid } \\
(2014)\end{array}$ & $\begin{array}{l}\text { Semai } \\
\text { Pancang } \\
\text { Pohon }\end{array}$ & $\begin{array}{l}3 \\
5 \\
4\end{array}$ & $\begin{array}{l}4.161 \\
2.880 \\
1.753\end{array}$ & $\begin{array}{l}\text { Baik, Sangat } \\
\text { padat } \\
\text { Baik, Sangat } \\
\text { padat } \\
\text { Baik, Sangat } \\
\text { padat }\end{array}$ \\
\hline $\begin{array}{l}\text { Aceh } \\
\text { Timur }\end{array}$ & $\begin{array}{l}\text { Ezwardi } \\
(2009)\end{array}$ & $\begin{array}{l}\text { Semai } \\
\text { Pancang } \\
\text { Pohon }\end{array}$ & $\begin{array}{l}15 \\
23 \\
12\end{array}$ & $\begin{array}{c}180.915 \\
13.058 \\
1.024\end{array}$ & $\begin{array}{l}\text { Baik, Sangat } \\
\text { padat } \\
\text { Baik, Sangat } \\
\text { padat } \\
\text { Rusak, Sedang }\end{array}$ \\
\hline $\begin{array}{c}\text { Aceh } \\
\text { Tamiang }\end{array}$ & $\begin{array}{c}\text { Aswita dan } \\
\text { Syahputra } \\
(2012)\end{array}$ & $\begin{array}{l}\text { Semai } \\
\text { Pancang } \\
\text { Pohon }\end{array}$ & $\begin{array}{l}2 \\
3 \\
2\end{array}$ & $\begin{array}{c}110.000 \\
5.840 \\
215\end{array}$ & $\begin{array}{l}\text { Baik, Sangat } \\
\text { padat } \\
\text { Baik, Sangat } \\
\text { padat } \\
\text { Rusak, Jarang }\end{array}$ \\
\hline
\end{tabular}

Sumber: Aswita dan Syahputra (2012); Ezwardi (2009); Majid (2014). Kriteria menurut Kementerian Lingkungan Hidup (2004): Baik, Sangat Padat (Kerapatan $>1.500)$, Rusak Sedang (1000 < Kerapatan < 1.500), dan Rusak Jarang (Kerapatan < 1.000).

Source : Aswita and Syahputra (2012); Ezwardi (2009); Majid (2014)

Criteria according to the Ministry of Environment (2004): good, very dense (density > 1.500), moderately damaged (1.000 < density < 1.500), and rarely damaged (density < 1.000)

Berdasarkan Tabel 4, dari beberapa hasil penelitian yang telah dilakukan sebelumnya, menunjukkan bahwa kondisi hutan mangrove untuk 3 wilayah studi umumnya baik, kecuali pada tingkat pohon di Aceh Timur dan Aceh Tamiang, yaitu rusak sedang dan rusak jarang. Jumlah tingkat semai dan pancang yang besar menunjukkan tingkat keberlanjutan ekologi mangrove akan berjalan dengan baik, jika aturan-aturan kelembagaan dipatuhi dan ditegakkan dalam menunjang kelestarian mangrove. Tingginya tingkat regenerasi mangrove setelah adanya gangguan akibat penebangan, ini menunjukkan adanya ketersediaan yang cukup akan pohon benih sebagai penghasil propagul (Ashton dan Macintosh 2002). Kondisi ini telah membuat masyarakat DPK di Aceh Tamiang beradaptasi untuk melakukan perubahan (redesign) terhadap kelembagaannya setelah menemukan bahwa aturan lokal (berdasarkan aturan tak tertulis) tidak cukup untuk melindungi sumber daya mangrove mereka dalam skala yang luas, yaitu dengan membuat aturan tertulis.

Praktik-praktik rehabilitasi lahan, pembibitan dan penanaman mangrove adalah usaha-usaha yang telah dilakukan oleh masyarakat DPK bekerjasama dengan Badan Pengelolaan Hutan Mangrove (BPHM), di samping patroli-patroli rutin yang mereka lakukan sebagai upaya perlindungan dan pengamanan area hutan mangrove yang merupakan bagian kerjasama dengan $\mathrm{KPH}$ wilayah 3. 


\section{Co-mangement sebagai Alternatif Pengelolaan}

Pengelolaan kolaboratif atau co-manajemen diartikan sebagai kesepakatan dua atau lebih pemangku kepentingan untuk membagi informasi, peran, fungsi, dan tanggung jawab dalam suatu hubungan dan mekanisme kemitraan yang disetujui secara bersama (Borrini-Feyerabend et al. 2000). Co-manajemen juga diartikan sebagai pembagian kekuasaan dan tanggung jawab antara pemerintah dan pengguna lokal atas sumber daya (Berkes 2002). Selanjutnya, co-manajemen didefinisikan sebagai berbagi tanggung jawab, hak, dan kewajiban antara pemangku kepentingan utama khususnya masyarakat lokal dan negara; pendekatan desentralisasi yang melibatkan pengguna lokal dalam proses pengambilan keputusan setara dengan negara (Bank Dunia 1999). Dalam proses mencapai tujuan seringkali dilakukan penyesuaian terus menerus atau adaptif (Carlsson dan Berkes 2005).

Hutan mangrove yang dikelola bersama (co-manajement), menunjukkan serangkaian pengaturan pengelolaan antara pengguna sumber daya lokal dan pemerintah. $\mathrm{Hal}$ ini berkisar dari pengaturan yang melibatkan peserta lokal hingga pengaturan di mana masyarakat lokal memiliki wewenang dan tanggung jawab yang besar. Artinya, masyarakat lokal pegguna sumberdaya dapat melakukan tugas pemeliharaan dan pengelolaan mangrove dilakukan atas dasar kesadaran dan kemandirian karena kekuasaan dipegang para pemangku kepentingan yang secara bersama-sama selalu belajar untuk melakukan pengelolaan yang lebih baik.

Partisipasi adalah kunci sukses mencapai co-manajemen. Sebagai pemangku kepentingan yang secara langsung memanfaatkan sumber daya mangrove, perananan masyarakat lokal dapat menjadi perusak atau pemelihara. Untuk memperkuat peranan dan fungsi masyarakat lokal sebagai pengelola mangrove, pemerintah diharapkan dapat mengakui hak-hak adat. Penegakan aturan-aturan adat oleh masyarakat memungkinkan dapat menyelamatkan mangrove karena ada kepastian akses, hak-hak dan insentif untuk mengembangkan tata kelola mangrove.

Beberapa hal yang dapat diambil sebagai pembelajaran dari co-manajement antara masyarakat DPK dengan KPH (pemerintah), yaitu: (1) pengelolaan bersama antara masyarakat DPK dengan KPH sebagai bentuk mekanisme resolusi konflik dan pembagian tugas. Sistem co-manajement dapat berfungsi sebagai sarana penyelesaian konflik antara masyarakat pengguna sumber daya lokal dan negara (Singleton 1998). Ketika proses negosiasi tawar-menawar dalam menyiapkan perjanjian co-manajement yang mengkodifikasi hak dan tanggung jawab pihak yang terlibat juga berfungsi sebagai mekanisme jangka panjang pemecah masalah. (2) Sebagai pertukaran sumber daya di mana kelompok masyarakat lokal membutuhkan beberapa jenis sumber daya yang mereka sendiri tidak mampu menyediakan, seperti teknologi dan beragam informasi. Namun, mereka memiliki sumber daya seperti informasi tentang kondisi atau status sumber daya mangrove yang dibutuhkan oleh $\mathrm{KPH}$. Sehingga terjadi hubungan jaringan di mana satu pihak tergantung pada sumber daya dan dikendalikan/dikontrol oleh yang lain karena memiliki pengetahuan tertentu, informasi atau legitimasi. (3) sebagai sarana menghubungkan berbagai jenis organisasi di mana berbagai jenis organisasi tersebut saling mengkoordinasikan kegiatan mereka dalam kaitannya dengan sistem sumber daya.

(4) Membangun kapasistas sebagai upaya yang diperlukan untuk memelihara, meningkatkan, dan memanfaatkan keterampilan dan kemampuan orang dan lembaga. Hal ini didasarkan pentingnya pengaturan kelembagaan sesuai kebijakan pemerintah dan kerangka hukum serta partisipasi pemangku kepentingan. 


\section{KESIMPULAN DAN SARAN}

Kelembagaan pada masyarakat DPK telah mengalami suatu adaptasi perubahan sosial (perubahan aturan, perubahan nilai, hubungan kekuasaan dalam masyarakat). Proses sosial ini memungkinkan untuk mengembangkan kelembagaan masyarakat DPK dalam bentuk co-management sehingga model kelembagaan inilah yang paling sesuai dalam mengatasi persoalan tumpang tindih property right, kelestarian ekologi mangrove, pengakuan hak-hak masyarakat terhadap pengelolaan mangrove, dan sebagai sumber penghidupan. Pentingnya lembaga akan memberikan insentif untuk keberlanjutan pengelolaan sumber daya mangrove. Akibat dari kemunduran ekologis mangrove membuat masyarakat DPK berusaha memperbaiki kelembagaannya agar keberlanjutan ekologi mangrove di wilayah mereka tetap terjamin kelestariannya. Para pembuat kebijakan kehutanan akan sangat diuntungkan dengan kerjasama yang dijalin oleh $\mathrm{KPH}$ dengan masyarakat lokal, karena akan sangat berkontribusi sebagai garda terdepan dalam perlindungan mangrove, di samping pengakuan hak-hak masyarakat lokal menjadi cukup penting sebagai insentif dalam pengelolaan mangrove.

Penulis menyampaikan ucapan terima kasih yang mendalam kepada Kementerian Riset, Teknologi, dan Pendidikan Tinggi, Direktorat Jenderal Sumber Daya Sains \& Teknologi, dan Pendidikan Tinggi Indonesia atas beasiswa dan dukungan untuk mendanai dan menyelesaikan penelitian ini.

\section{DAFTAR PUSTAKA}

Agrawal A., Chhatre A. 2006. Explaining success on the commons: community forest governance in the Indian himalayas. World Development. 34, 49-166. doi:10.1016/j.worlddev.2005.07.01

Agrawal A., Gupta K. 2005. Decentralization and participation: the governance of common pool resources in Nepal's Terai. World Development. 33 (7), 1101-1114. https://doi.org/10.1016/i.worlddev.2005.04.009

Adhikari KP., Goldey P. 2010. Social capital and its "downside": The impact on sustainability of induced community-based organizations in Nepal. World Development 38 (2): 184-194. DOI: 10.1016/i.worlddev.2009.10.012

Alcorn J., Kajuni A., Winterbottom B. 2002. Assessment of CBNRM best practices in Tanzania. Final Report for USAID, Tanzania.

Anshari GZ. 2006. Dapatkah pengelolaan kolaboratif menyelamatkan Taman nasional Danau Sentarum? Center for International Forestry Research [CIFOR]. Bogor.

Asthon EC., Macintosh DJ. 2002. Preliminary assessment of the plant diversity and community ecology of Sematan mangrove forest, Serawak, Malaysia. Forest Ecology and Management 166: 111-129. DOI: 10.1016/S0378-1127(01)00673-9

Aswita., Syahputra, OH. 2012. Integrated coastal management in Pusong Cium Island for habitat of tuntong laut (Batagur borneoensis), District of Seuruway, Aceh Tamiang Regency, Aceh Province-Indonesia. Laporan Hasil Penelitian. Banda Aceh: Sekolah Tinggi Ilmu Kehutanan Yayasan Teungku Chik Pante Kulu, Banda Aceh.

Berkes F. 2008. Sacred Ecology: Traditional ecological knowledge and resource management. Philadelphia, PA: Taylor \& Francis.

Berkes F, 2002. Cross-scale institutional linkages: perspectives from the bottom up. In: Ostrom E., Dietz T., Dolsak N., Stern PC., Stonich S., Weber EU. (Eds.), The Drama of the Commons. National Academy Press, Washington DC, pp. 293-321.

Bhattacharya P., Pradhan L., Yadav G. 2010. Joint forest management in India: Experiences of two decades. Resources, Conservation, and Recycling 54 (8): 
469-480. DOI: 10.1016/j.resconrec.2009.10.003

Borrini-Feyerabend G., Farvar MT., Nguinguiri JC., Ndangang V. 2000. Comanagement of natural resources: Organizing negotiation and learning by doing Kasparek, Heidelberg (Germany). http://nrm.massey.ac.nz/changelink/cmnr.html

Brockington D. 2007. Devolution, community conservation and forest. On local government performance and village forest reserves in Tanzania. Society and Natural Resources 20, 835-848. https://doi.org/10.1080/08941920701460366

Bromley DW. 1989. Economic Interest and Institutions: The Conceptual Foundations of Public Policy. Basil Blackwell, New York. DOI: https://doi.org/10.1017/ S0266267100003126

Caballero G., Varella MM., Garza MD. 2014. Institutional change, fishing rights and governance mechanisms: the dynamics of the spanish 300 fleet on the grand sole fishing grounds. Marine Policy 44, 465-472.

Carlson LM., Doyle J. 2002. Complexity and robustness. PNAS 99, 2538-2545.

Carlson L., Sandstrom A. 2008. Network governance of the commons. International Journal of the Commons 1 (2): 33-54.

Carlsson L., Berkes F. 2005. Comanagement: concepts and methodological implications. Journal of Environmental Management 75: 65-76. doi:10.1016/j.jenvman.2004.11.008

Cornwall A., Jewkes R. 1995. What is participatory research?. Social Sciense Medicine, 41 (12) 1667-1676. https://doi.org/10.1016/0277-9536(95)00127-5

Ezwardi I. 2009. Struktur vegetasi dan mintakat hutan mangrove di Kuala Bayeun, Kabupaten Aceh Timur, Provinsi Nanggroe Aceh Darussalam. [Skripsi]. Bogor: Institut Pertanian Bogor.

Harrison S., Suh J. 2004. Progress and Prospects of community forestry in developing and developed countries. Small-Scale Forest Economics, Management and Policy (3) 3. 278-302.

Hayes TM. 2006. Park, people, and forest protection: an institutional assessment of the effectiveness of protected areas. World Development 34 (12) 2064-2075. doi:10.1016/j.worlddev.2006.03.002

Hidayat A. 2005. Institutional Analysisof Coral Reef Management: Case Study of Gili Indah Village, West Lombok, Indonesia. Shaker Verlag, Aachen.

Janssen MA., Holahan R., Lee A., Ostrom E. 2010. Laboratorium expriments for the study of social-ecological systems. Science 358, 613-617. DOI: 10.1126/science. 1183532

Kathiresan L., dan Bingham BL. 2001. Biology of Mangroves and Mangrove Ecosystems. Advances in Marine Biology Vol 40: 81-251. Parangipettai-India. https ://doi.org/10.1016/S0065-2881 (01) 40003-4

Kementerian Negara Lingkungan Hidup. 2004. Kumpulan peraturan pengendalian

kerusakan pesisir dan laut. Deputi bidang peningkatan konservasi sumberdaya alam dan pengendalian kerusakan lingkungan.

Knight J. 1992. Institutions and Social Conflict. Cambridge University Press, New York.

Kusmana C. 2012. Management Mangrove Ecosystem in Indonesia. Paper Presented in Workshop on Mangrove Re-Plantation and Coastal System Rehabilitation. Faculty of Forestry, Gadjah Mada University, Yogyakarta.

Majid, AB. 2014. Studi potensi ekowisata mangrove di Kuala Langsa, Provinsi Aceh. [Skripsi]. Medan: Universitas Sumatera Utara.

McGinnis MD. 2011. An introduction to IAD and the language of the Ostrom workshop: a simple guide to a complex framework. The Policy Studies Journal, Vol 39: 1. DOI: $10.1111 / \mathrm{j} .1541-0072.2010 .00401 . x$

Mukul SA., Uddin MB., Rashid AZM., Fox J. 2010. Integrating livelihoods and conservation in protected areas: Understanding the role and stakeholder views on prospects for non-timber forest products, a Bangladesh case. International 
Journal of Sustainable Development and World Ecology 17 (2): 180-186. https://doi.org/10.1080/ 13504500903549676

Muttaqin MZ. 2012. Pengelolaan Lahan dan Hutan di Indonesia: Akses Masyarakat Lokal Ke Sumber daya Hutan dan Pengaruhnya pada Pembayaran Jasa lingkungan dalam Muttaqin MZ, Subarudi (eds). Pengelolaan Kawasan Hutan dan Lahan dan Pengaruhnya bagi Pelaksanaan REDD+ di Indonesia: Tenure, Stakeholder dan Livelihoods. Pusat Penelitian dan Pengembangan Perubahan Iklim dan Kebijakan, Badan Penelitian dan Pengembangan Kehutanan, Bogor.

Nelson A., Chomitz KM. 2009. Protected area effectiveness in reducing tropical deforestation: a global analysis of the impact of protection status. Independent Evaluation Group Evaluation Brief 7.

North CD. 1990. Instituions, Institutional Change and Economic Performance. Cambridge University Press. New York. USA.

Nugroho B. 2013. Reformasi kelembagaan dan tata kepemerintahan: Faktor pemungkin menuju tata kelola kehutanan yang baik dalam Kartodihardjo $\mathrm{H}$. (ed): "Kembali Ke Jalan Lurus: Kritik Penggunaan IImu dan Praktek Kehutanan Indonesia". Forci Development dan Tanah Air Beta, Yogyakarta.

Nursidah., Nugroho B., Darusman D., Rusdiana O., Rasyid Y. 2012. Pengembangan institusi untuk membangun aksi kolektif lokal dalam pengelolaan hutan kawasan lindung SWP DAS Arau, Sumatera Barat. Jurnal Manajemen Hutan Tropika, Vol. XVIII, (1): 18-30 DOI: 10.7226/jtfm.18.1.18.

Ostrom E. 1990. Governing the commons: the evaluation of institutions for collective action. Cambridge University Press, United Kingdom.

Ostrom E. 1999. Institutional rational choice: an assessment of the institutional analysis and development framework. In: Sabatier P (ed). Theories of the Policy Process: Theoretical Lenses on Public Policy. Westview Press, Boulder Co, pp. 35-71.

Ostrom E. 2005. Understanding Institutional Diversity. Princeton and Oxford: Princeton University Press.

Ostrom E. 2011. Background on The Institutional Analysis and Development Framework. The Policy Studies Journal 39 (1): 7-27. DOI: 10.1111/j.1541$\underline{0072.2010 .00394 . x}$

Phan Nguyen Hong (ed). 2006. The Role of Mangrove and Coral Reef Ecosystem in Natural Disaster Mitigation and Coastal Life Improvement. World Conservation Union: Hanoi, Vietnam.

Pidgeon E. 2009. Carbon Sequestration by Coastal Marine habitats: Important missing Sink. In The Management of Natural Coastal Carbon Sink. IUCN: Gland, Switzerland.

Roy AKD., Alam K., Gow J. 2012. A review of the role of property rights and forest policies in management of the Sundarbans mangrove forest in Bangladesh. Forest Policy and Economics 15 (1): 46-53. DOI: 10.1016/j.forpol.2011.08.009

Roy AKD., Alam K. 2012. Participatory forest management for the sustainable management of the Sunderbans mangrove forest. American Journal of Environmental Sciences 8 (5): 549-555. DOI: 10.3844/ajessp.2012.549.555

Schweik CM. 1998. Sosial norms and human foraging an investigation into the spatial distribution of Shorea robusta in Nepal. In: Gibson C., McKean M, and Ostrom E (Eds). Forest resources and Institutions. Forest, Tress and People Programme, Working Paper 3. FAO, Rome, Italy.

Scott WR, 2008. Institutions and Organizations: Ideas and Interests. SAGE Publications, Thousand Oaks.

Singleton S. 1998. Constructing Cooperation: the Evolution of Institutions of Comanagement. University of Michigan Press, Ann Arbor.

Sithole B. 1997. The Institutional frameworks for the management and use of natural resources in communal areas of Zimbabwe: village cases of access to and use of dambos from Mutoko and Chiduku. CASS, University of Zimbabwe, Harare.

Soontornwong S. 2006. Improving livelihood through CBNRM: a case of self- 
organization in community mangrove management in Thailand. in Mahanty $S$, Fox J, Nurse M, Stephen P, and McLees L, editors. Hanging in the balance: equity in community-based natural resource management in Asia. East-West Center, Honolulu, Hawaii, USA. pp 182-199.

Sudtongkong C., Webb EL. 2008. Outcomes of state vs community based mangrove management in southern Thailand. Ecology and Society 13 (2), 27-50. http://www.ecologyandsociety.org/vol13/iss2/art27/ 